\title{
Prototype Telecontrolling Pintu Air Otomatis pada Pengairan Lahan Berbasis Android
}

\author{
Firda Amalia Romana ${ }^{1}$, Moh.Abdullah Anshori², Mochammad Junus ${ }^{3}$ \\ 1,2,3 Program Studi Jaringan Telekomunikasi Digital, \\ Jurusan Teknik Elektro, Politeknik Negeri Malang, Indonesia
}

1irdaamaliar@gmail.com, ${ }^{2}$ moh.abdullah@polinema.ac.id, ${ }^{3}$ moch.junus@polinema.ac.id

\begin{abstract}
The need of water in each land varies depending on the area and conditions of the land. In addition, the technology is still done manually. We need a lot of time to irrigate the plants therefore it is not effective. An efforts must be made to optimize water management, such as on time, on quantity, and on target, as well as covering a large area. This research proposes an android-based automatic floodgate telecontrolling system by utilizing a Soil Moisture sensor and an android application. Relays are used as opening and closing sluices. The results of the relay status when on or off and the humidity value will enter the application and can be monitored in real time. The test results show that the Soil Moisture Sensor can detect Soil Moisture with an average error of $0.362 \%$. The control and monitoring system through the application using Android is in accordance with the plan with an average delay for ON / OFF status and a humidity value of $0.487295 \mathrm{~s}$.
\end{abstract}

Keywords - Android, Relay, Soil Moisture

Abstrak - Kebutuhan air di masing-masing lahan berbeda-beda tergantung luas lahan dan kondisi lahan. Selain itu teknologi tersebut masih dilakukan secara manual dan memerlukan waktu yang tidak sedikit hanya untuk mengairi tanaman sehingga tidak efektif. Menyiasati hal tersebut pengelolaan air harus diusahakan secara optimal yaitu tepat waktu, tepat jumlah, dan tepat sasaran, dan juga menjangkau area yang luas sehingga efisien. Pada penelitian ini diusulkan system telecontrolling pintu air otomatis berbasis android dengan memanfaatkan sesnsor Soil Moisture dan aplikasi android. Hasil pengukuran kelembaban tanah yang diambil serta waktu yang diinputrkan pada aplikasi android ini akan merubah status relay yang digunakan sebagai pembuka dan penutup pintu air. Hasil status relay saat on atau off dan nilai kelembaban ini akan masuk kedalam aplikasi dan dapat dimonitoring secara real time. Hasil pengujian dapat disimpulkan bahwa Sensor Soil Moisture ini dapat mendeteksi kelembaban tanah dengan rata rata error sebesar $\mathbf{0 , 3 6 2 \%}$. Sistem kontroling dan monitoring melelalui aplikasi menggunakan android sesuai dengan perencanaan dengan rata rata delay untuk status ON/OFF dan nilai kelembabab sebesar 0.487295s.

Kata kunci-Android, Kelembapan tanah, Relay

\section{PENDAHULUAN}

Di negara kita pertanian/perkebunan merupakan sumber utama dalam memenuhi kebutuhan pangan. Di dalam pertanian/perkebunan, air adalah hal yang sangat penting untuk memenuhi kebutuhan tumbuhan.Pengaturan pembagian atau pengaliran air menurut sistem tertentu di sawah/lahan pertanian disebut irigasi[1].

Kebutuhan air di masing-masing lahan berbeda-beda tergantung luas lahan dan kondisi lahan, apakah kering, semi kering, lembab atau basah. Kondisi ini mempengaruhi air yang dibutuhkan untuk pengairan lahan tersebut. Selain itu teknologi tersebut masih dilakukan secara manual dan memerlukan waktu yang tidak sedikit hanya untuk mengairi tanaman sehingga tidak efektif [2]. Misalnya para petani harus menunggu untuk mematikan pompa air atau menyiram satu persatu lahan. Menyiasati hal tersebut pengelolaan air harus diusahakan secara optimal yaitu tepat waktu, tepat jumlah, dan tepat sasaran, dan juga menjangkau area yang luas sehingga efisien.

Adapun penelitian yang berhubungan dengan buka tutup pintu air otomatis yang sebelumnya sudah dilakukan[2], dalam penelitian tersebut dijelaskan tentang telemonitoring pintu air irigasi otomatis, namun dalam penelitian tersebut interface yang digunakan sebuah web dimana web tersebut harus diakses melalui Pc atau laptop dimana alat tersebut dapat dikatakan kurang efektif. Dikarenakan penggunaan PC atau Laptop sendiri tidak semua orang mempunyai laptop atau PC, untuk mengaksesnya juga membutuhkan ruang.

Dari hal tersebut maka peneliti akan menggunakan mikrokontroler Arduino untuk pengumpulan data yang diambil dari beberapa sensor yang berupa data kadar air dalam 3 lahan, data yang dikumpulkan juga berupa data dari berbagai studi literature untuk kebutuhan air pada setiap jenis tanah. Data akan diolah oleh mikrokontroler untuk perintah mengaktiflkan pompa air ini dapat diakses melalui aplikasi android dimana pompa akan menyala sesuai perintah[3], terdapat 4 pilihan untuk membuka pintu air pada setiap jenis pengairan yang dipilih. Pompa akan menyala untuk mengairi lahan sesuai batas bawah kadar air dalam tanah dan menutup ketika keadar air sudah mencapai batas atas. Tingkat kadar air pada lahan akan dikirim ke aplikasi android melalui jaringan wifi. Jadi user atau pengguna dapat mengetahui tingkat kadar air dari tanah tersebut melalui aplikasi android. 
Kelebihan dari sitem ini adalah pengguna dapat mengontrol dan memonitoring air dan kelembapan tanah secara bersamaan dengan menggunakan 1 aplikasi, selain itu interface pada aplikasi ini akan dibuat sesederhana mungkin untuk memudahkan petani dalam menggunakan aplikasi ini.

\section{METODE}

\section{A. Blok Diagram Sistem}

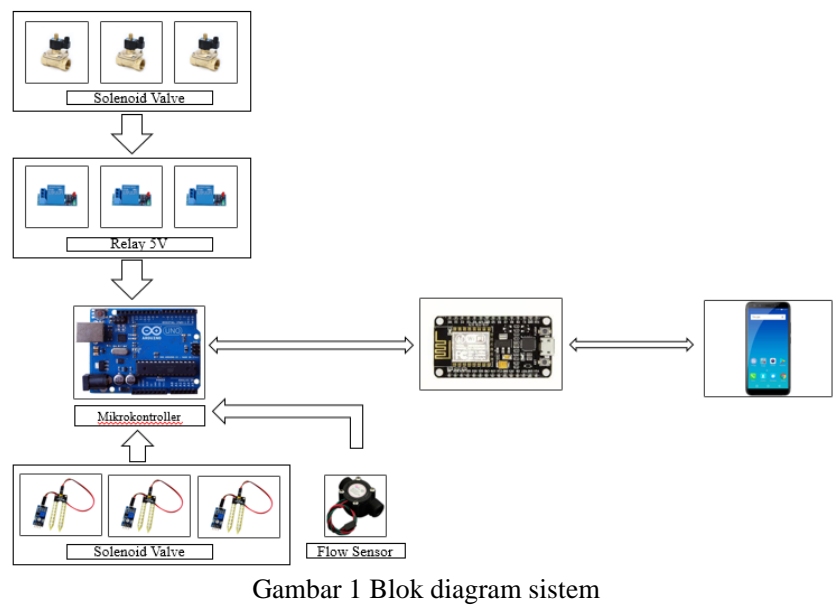

Pada Gambar 2 dijelaskan bahwa, pengguna aplikasi digunakan untuk mengontrol pintu air serta dapat memilih berbagai pilihan untuk pengairan lahannya, pada aplikasi akan ada 3 pilihan pengairan untuk lahan sesuai dengan kriteria masing-masing, pilihan tersebut berupa pengairan untuk membuka lahan baru, pengairan untuk tanaman, dan pengairan untuk lahan akan panen. Soil Moisture digunakan untuk membaca kelembapan (Kadar Air) dalam tanah secara real time.

Pengguna dapat memilih salah satu pilihan tersebut lalu data kelembapan yang sudah diolah akan menggerakkan solenoid, selenoid akan terbuka setiap kelembapan melewati batas bawah, dan akan tertutup setiap melewati batas atas. Selenoid akan berkerja seperti itu terus menerus dalam waktu yang ditentukan, tergantung penggunaan pengairan.Tingkat kadar air dalam tanah akan secara real time dikirim ke aplikasi melalui wifi yang tersedia. Pengontrolan pintu air ini dilakukan juga melalui aplikasi andorid. Batas bawah dan batas atas kelembapan tanah, serta waktu yang dibutuhkan untuk pengairan sudah ditentukan dan diinputkan kedalam arduino untuk diolah.

\section{B. Flowchart Alur Kerja Program}

Setelah masuk kedalam aplikasi pengguna diminta untuk memasukkan instruksi, pada aplikasi ada 1 pilihan pertama yaitu pengguna diminta untuk memilih membuka pintu air, untuk pembuka pintu air telah disediakan 3 pilihan bentuk pengairan, pada 3 pilihan bentuk pengairan ini tingkat kelembapan sudah disetting setpointnya pada arduino, setelah memilih salah satu dari ketiga pilihan tersebut pengguna dapat memilih lahan mana yang mau dialiri air, disini terdapat 4 pilihan buka pintu air dengan 3 lahan dengan tingkat kadar air yang berbeda. Flowchart alur kerja program ditunjukkan Gambar 2.

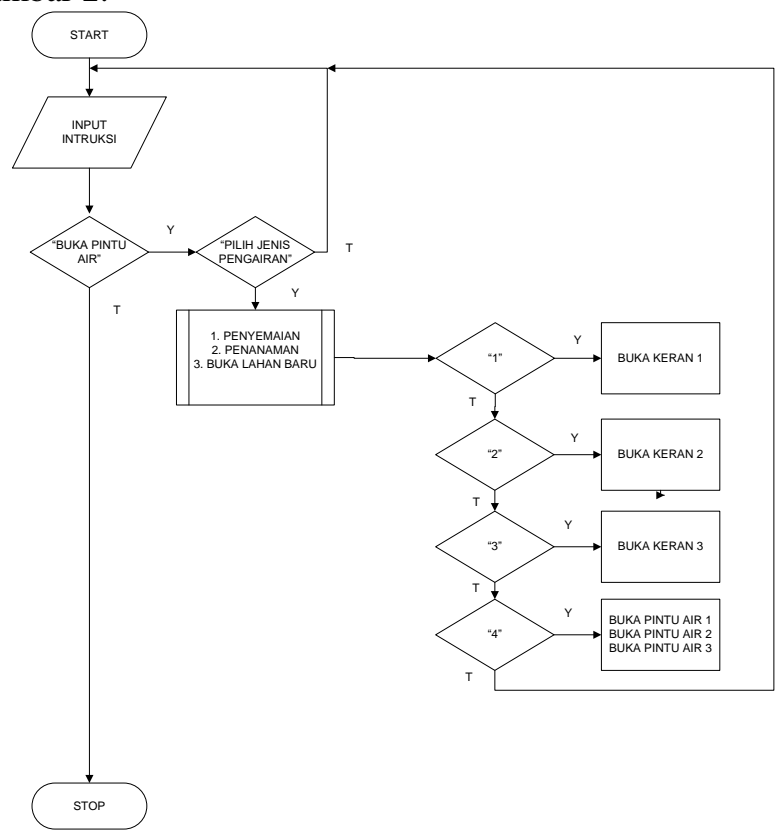

Gambar 3 Flowchart alur cara kerja aplikasi

\section{Analisa}

Saat terjadi pengiriman data kita mengambil QoS yaitu delay dan packet data dengan menggunakan protocol html dan protocol mqtt, lalu membandingakan membandingkan performasi protocol mqtt dengan protocol http-get untuk mengetahui kelebihan setiap protocol dan apakah lebih baik protocol mqqt atau protocol http-get untuk sistem seperti ini, ditunjukkan pada Gambar 3.

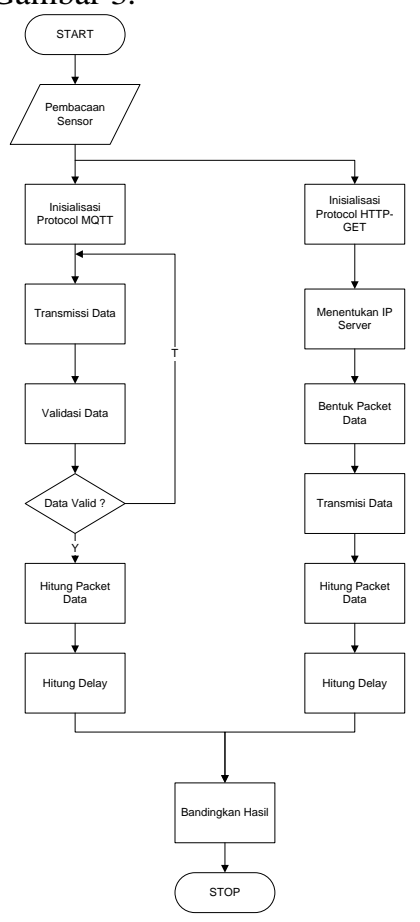

Gambar 4 Prosedur analisis pengiriman data 


\section{HASIL DAN PEMBAHASAN}

Tahap Pengujian ini terdiri dari prosedur pengujian yang akan didapatkan hasil berupa data hasil pengujian sesuai parameter

A. Pengujian Sensor Soil Moisture

TABEL I

NILAI KELEMBAPAN TANAH

\begin{tabular}{|c|c|c|c|c|c|c|c|}
\hline \multirow{2}{*}{ No } & \multicolumn{3}{|c|}{$\begin{array}{c}\text { Nilai Kelembapan } \\
\text { Sensor }\end{array}$} & \multirow{2}{*}{ Alat } & \multicolumn{3}{|c|}{$\begin{array}{l}\text { Kesalahan Pembanding } \\
\text { Pembacaan Sensor }\end{array}$} \\
\hline & S1 & S2 & S3 & & S1 & S2 & S3 \\
\hline 1 & 10 & 10 & 10 & 10 & $0 \%$ & $0 \%$ & $0 \%$ \\
\hline 2 & 38 & 29 & 28 & 30 & $\begin{array}{c}0,26 \\
\%\end{array}$ & $\begin{array}{c}0,03 \\
\%\end{array}$ & $0,067 \%$ \\
\hline 3 & 46 & 40 & 37 & 40 & $\begin{array}{c}0,15 \\
\%\end{array}$ & $0 \%$ & $0,075 \%$ \\
\hline 4 & 60 & 55 & 51 & 60 & $0 \%$ & $\begin{array}{c}0,08 \\
3 \%\end{array}$ & $0,15 \%$ \\
\hline 5 & 78 & 83 & 79 & 80 & $\begin{array}{c}0,02 \\
5 \%\end{array}$ & $\begin{array}{c}0,03 \\
7 \%\end{array}$ & $0,012 \%$ \\
\hline 6 & $\begin{array}{c}10 \\
1\end{array}$ & 103 & 99 & 100 & $\begin{array}{c}0,01 \\
\%\end{array}$ & $\begin{array}{c}0,03 \\
\%\end{array}$ & $0,01 \%$ \\
\hline
\end{tabular}

Dari hasil pengujian yang telah dilakukan, pada Tabel I didapatkan nilai kelembaban tanah saat kondisi kering pada sensor 1 adalah 10, nilai kelembaban pada sensor 2 adalah 10 , kelembaban pada sensor 3 adalah 10 dengan nilai pengukuran pada soil meter yaitu 10, dari 3 sensor tersebut didapatkan nilai error secara berurutan yaitu 0, 0, dan 0.Keadaan tanah yang paling basah nilai sensor 1 adalah 101, nilai sensor 2 adalah 103 , nilai sensor 3 adalah 99 dengan nilai error secara berurutan yaitu $0.01 \%, 0.03 \%$ dan 0.01 . Rata rata nilai error terbesar terjadi pada sensor 1 yaitu pada kelembaban 30, dan 40 sebesar $0,26 \%$ dan $0,15 \%$.

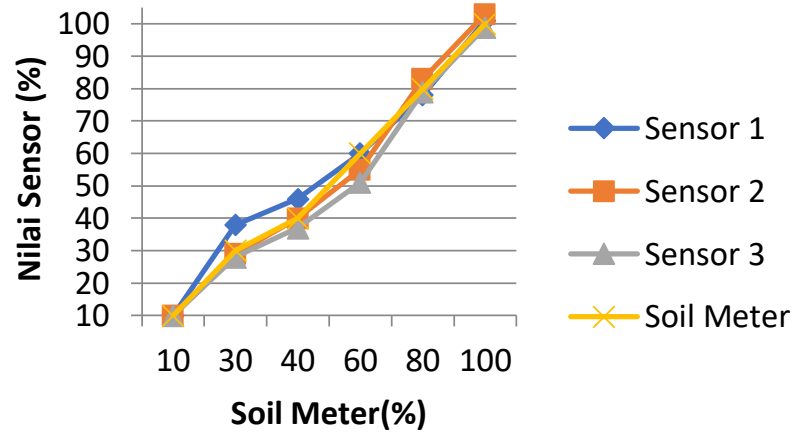

Gambar 5. Grafik uji coba sensor soil moisture

Perbandingan nilai sensor Soil Moisture dengan soil meter ini memiliki nilai hampir berdekatan sampai titik kelembapan $100 \%$. Hal ini ditunjukkan dari bentuk grafik nilai soil meter da hasil pengukuran yang tidak memiliki selisih yang cukup jauh. Seperti yang ditunjukkan pada Gambar 4.

\section{B. Pengujian Relay}

TABEL II

STATUS RELAY PADA MASING-MASING TANAH

\begin{tabular}{|c|c|c|c|c|c|}
\hline No & $\begin{array}{l}\text { Jenis } \\
\text { Lahan }\end{array}$ & $\begin{array}{l}\text { Mode Yang } \\
\text { Digunakan }\end{array}$ & $\begin{array}{l}\text { Titik } \\
\text { Point }\end{array}$ & $\begin{array}{c}\text { Nilai } \\
\text { Kelembaban } \\
\text { Pintu } \\
\text { Tertutup }(\%) \\
\end{array}$ & $\begin{array}{l}\text { Rata- } \\
\text { Rata }\end{array}$ \\
\hline \multirow{3}{*}{1} & \multirow{3}{*}{$\begin{array}{c}\text { Lahan } 1 \\
\text { (Ket : } \\
\text { berupa } \\
\text { tanah } \\
\text { sawah } \\
\text { untuk } \\
\text { padi ) }\end{array}$} & $\begin{array}{c}\text { Buka Lahan } \\
\text { Baru } \\
\text { (Ket : } \\
\text { Kelembaban } \\
\text { tercapai saat } \\
\text { 40-60\%) }\end{array}$ & 3 & 50 & $58 \%$ \\
\hline & & $\begin{array}{c}\text { Penyiangan } \\
\text { (Ket : } \\
\text { Kelembaban } \\
\text { tercapai saat } \\
40-60 \%)\end{array}$ & 2 & $\begin{array}{l}101 \\
61\end{array}$ & $64 \%$ \\
\hline & & $\begin{array}{c}\text { Penyemaian } \\
\text { (Ket : } \\
\text { Kelembaban } \\
\text { tercapai saat } \\
40-60 \% \text { ) }\end{array}$ & $\begin{array}{l}1 \\
2\end{array}$ & $\begin{array}{l}25 \\
104 \\
104\end{array}$ & $77,7 \%$ \\
\hline \multirow{3}{*}{2} & \multirow{3}{*}{$\begin{array}{c}\text { Lahan } 2 \\
\text { (Ket : } \\
\text { berupa } \\
\text { tanah } \\
\text { ladang } \\
\text { untuk } \\
\text { cabai ) }\end{array}$} & $\begin{array}{c}\text { Buka Lahan } \\
\text { Baru } \\
\text { (Ket : } \\
\text { Kelembapan } \\
\text { tercapai saat } \\
70 \%-80 \%)\end{array}$ & 3 & 79 & $86,5 \%$ \\
\hline & & $\begin{array}{c}\text { Penyiangan } \\
\text { (Ket : } \\
\text { Kelembapan } \\
\text { tercapai saat } \\
70 \%-80 \%)\end{array}$ & 2 & $\begin{array}{l}89 \\
76\end{array}$ & $82,7 \%$ \\
\hline & & $\begin{array}{c}\text { Penyemaian } \\
\text { (Ket : } \\
\text { Kelembapan } \\
\text { tercapai saat } \\
70 \%-80 \%)\end{array}$ & 1 & $\begin{array}{l}100 \\
83\end{array}$ & $91 \%$ \\
\hline \multirow{3}{*}{3} & $\begin{array}{c}\text { Lahan } 3 \\
\text { (Ket. }\end{array}$ & $\begin{array}{c}\text { Buka Lahan } \\
\text { Baru } \\
\text { (Ket : } \\
\text { Kelembapan } \\
\text { tercapai saat } \\
\text { 70\%-80\%) }\end{array}$ & 2 & 77 & $70,7 \%$ \\
\hline & $\begin{array}{c}\text { sampel } 3 \\
\text { berupa } \\
\text { tanah } \\
\text { ladang } \\
\text { berpasir } \\
\text { untuk }\end{array}$ & $\begin{array}{c}\text { Penyiangan } \\
\quad(\text { Ket : } \\
\text { Kelembapan } \\
\text { tercapai saat } \\
70 \%-80 \%)\end{array}$ & 3 & $\begin{array}{l}104 \\
80\end{array}$ & $94 \%$ \\
\hline & nipis) & $\begin{array}{c}\text { Penyemaian } \\
\text { (Ket : } \\
\text { Kelembapan } \\
\text { tercapai saat } \\
30 \%-40 \% \text { ) }\end{array}$ & 1 & 74 & $63,3 \%$ \\
\hline
\end{tabular}

Pengujian status relay pada Tabel II merupakan status relay pada masing masing tanah. Sesuai dengan pengujian diambil status relay sesuai dengan kelembaban yag sudah 
ditentukan. Sistem antara kelembaban dengan relay berjalan sesuai dengan perencanaan dan menghasilkan data yang stabil meskipun ada beberapa percobaan yang mempunyai selisih data tidak terlalu jauh berbeda antara data dengan perencanaan.

\section{Pengujian Flow Sensor}

TABEL III

PENGUJIAN FLOW SENSOR

\begin{tabular}{|c|c|c|c|c|c|}
\hline No & $\begin{array}{l}\text { Jenis } \\
\text { Lahan }\end{array}$ & $\begin{array}{c}\text { Mode } \\
\text { Yang } \\
\text { Digunak } \\
\text { an } \\
\end{array}$ & $\begin{array}{c}\text { Penunju } \\
\text { kkan } \\
\text { Awal } \\
\text { Meter } \\
\text { Air (mL) }\end{array}$ & $\begin{array}{c}\text { Penunjukka } \\
\text { n Akhir } \\
\text { Meter (mL) }\end{array}$ & $\begin{array}{c}\text { Total } \\
\text { Pemakai } \\
\text { an (L) }\end{array}$ \\
\hline 1 & $\begin{array}{l}\text { Lahan } 1 \\
\text { (Tanama } \\
\text { n Padi } \\
\text { Tanah } \\
\text { Sawah) }\end{array}$ & $\begin{array}{l}\text { Buka } \\
\text { Lahan }\end{array}$ & 23095 & 23658 & 0,563 \\
\hline 2 & $\begin{array}{l}\text { Lahan } 1 \\
\text { (Tanama } \\
\text { n Padi } \\
\text { Tanah } \\
\text { Sawah) }\end{array}$ & $\begin{array}{c}\text { Penyiang } \\
\text { an }\end{array}$ & 29355 & 30355 & 1 \\
\hline 3 & $\begin{array}{l}\text { Lahan } 1 \\
\text { (Tanama } \\
\text { n Padi } \\
\text { Tanah } \\
\text { Sawah) }\end{array}$ & $\begin{array}{c}\text { Penyemai } \\
\text { an }\end{array}$ & 1560 & 3289 & 1,729 \\
\hline 4 & $\begin{array}{c}\text { Lahan } 2 \\
\text { (Tanama } \\
\text { n Cabai } \\
\text { Tanah } \\
\text { Ladang) }\end{array}$ & $\begin{array}{l}\text { Buka } \\
\text { Lahan }\end{array}$ & 3363 & 4943 & 1,5 \\
\hline 5 & $\begin{array}{c}\text { Lahan } 2 \\
\text { (Tanama } \\
\text { n Cabai } \\
\text { Tanah } \\
\text { Ladang) }\end{array}$ & $\begin{array}{c}\text { Penyiang } \\
\text { an }\end{array}$ & 11383 & 13116 & 1,7 \\
\hline 6 & $\begin{array}{c}\text { Lahan } 2 \\
\text { (Tanama } \\
\text { n Cabai } \\
\text { Tanah } \\
\text { Ladang) }\end{array}$ & $\begin{array}{c}\text { Penyemai } \\
\text { an }\end{array}$ & 15922 & 17612 & 1,6 \\
\hline 7 & $\begin{array}{c}\text { Lahan } 3 \\
\text { (Tanama } \\
n \\
\text { JerukTan } \\
\text { ahPasir) }\end{array}$ & $\begin{array}{l}\text { Buka } \\
\text { Lahan }\end{array}$ & 763 & 3363 & 2,6 \\
\hline 8 & $\begin{array}{c}\text { Lahan } 3 \\
\text { (Tanama } \\
n \\
\text { JerukTan } \\
\text { ahPasir) }\end{array}$ & $\begin{array}{c}\text { Penyiang } \\
\text { an }\end{array}$ & 5493 & 7398 & 1,9 \\
\hline 9 & $\begin{array}{c}\text { Lahan } 3 \\
\text { (Tanama } \\
n \\
\text { JerukTan } \\
\text { ahPasir) }\end{array}$ & $\begin{array}{l}\text { Penyemai } \\
\text { an }\end{array}$ & 8857 & 10368 & 1,5 \\
\hline
\end{tabular}

\section{Pengujian Delay}

TABEL IV

PENGUJIAN DELAY

\begin{tabular}{ccc}
\hline \multirow{2}{*}{ No } & \multicolumn{2}{c}{ Delay } \\
\cline { 2 - 3 } & $\begin{array}{c}\text { Menggunakan Protocol } \\
\text { HTTP-GET }\end{array}$ & $\begin{array}{c}\text { Menggunakan Protocol } \\
\text { MQTT }\end{array}$ \\
\hline 1 & 0 & 0 \\
2 & 0.004871 & 0.044819
\end{tabular}

\begin{tabular}{ccc}
\hline & \multicolumn{2}{c}{ Delay } \\
\cline { 2 - 3 } No & $\begin{array}{c}\text { Menggunakan Protocol } \\
\text { HTTP-GET }\end{array}$ & $\begin{array}{c}\text { Menggunakan Protocol } \\
\text { MQTT }\end{array}$ \\
\hline 3 & 7.172423 & 0.000526 \\
4 & 14.539444 & 0.137145 \\
5 & 1.681148 & 0.002646 \\
6 & 8.000712 & 0.082335 \\
7 & 1.600219 & 0.000174 \\
8 & 1.598875 & 0.000111 \\
9 & 0.699922 & 0.004763 \\
10 & 4.101105 & 0.137924 \\
11 & 1.705228 & 0.019873 \\
12 & 1.5603 & 16.653332 \\
13 & 1.613851 & 0.034287 \\
14 & 0.736219 & 0.000379 \\
15 & 0.009987 & 0.529314 \\
16 & 2.506906 & 0.000269 \\
17 & 2.956112 & 0.005711 \\
18 & 1.722991 & 0.000257 \\
19 & 1.721961 & 0.006199 \\
20 & 3.631593 & 0.007553 \\
21 & 1.881032 & 0.293742 \\
22 & 12.194131 & 0.000889 \\
23 & 1.605528 & 0.000177 \\
24 & 2.396343 & 0 \\
25 & 0.647052 & 0.310966 \\
26 & 1.581947 & 0.223145 \\
27 & 1.614956 & 30.429443 \\
28 & 0.842943 & 0.115582 \\
29 & 0.751333 & 4.83758 \\
30 & 1.599226 & 0.349955 \\
Rata & 0.799613 & 0.1749775 \\
Rata & & \\
& &
\end{tabular}

Tabel IV merupakan pengujian delay. Dari perhitungan paket yang dihasilkan rata - rata delay yang diperoleh adalah delay mebggunakan protocol HTTP-GET sebesar 0.799613s sedangkan delay saat menggunakan protocol MQTT sebesar $0.025617 \mathrm{~s}$ dapat kita lihat bahwa hasil perhitungan delay sangat kecil.

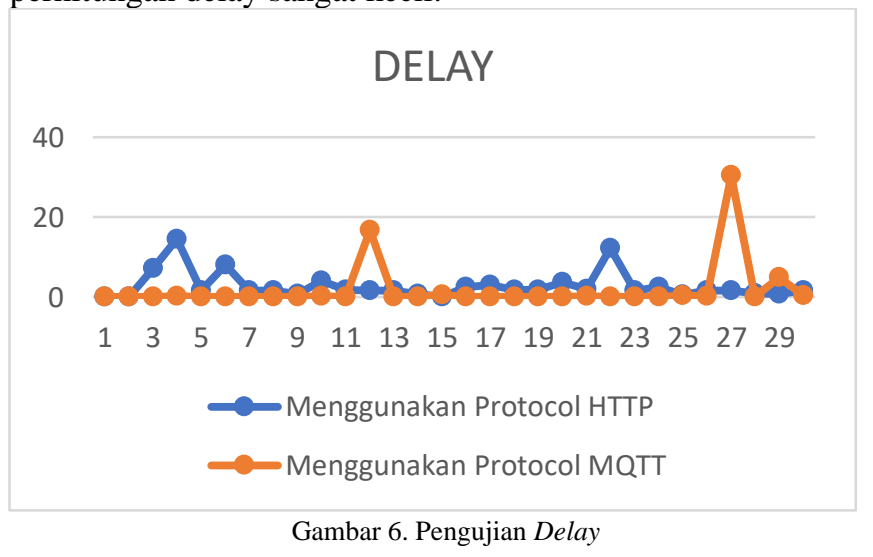

Semakin kecil delay maka akan semakin bagus kualitas suatu panggilan karena tidak akan terjadi keterlambatan informasi. Gambar 5 dapat dilihat juga bahwa perubahan kondisi pada status relay dan nilai kelembaban mempengaruhi delay pengiriman data dari server ke client. Selain itu dari grafik tersebut protocol MQTT nilai delaynya lebih kecil dan stabil dibandingkan dengan delay Protocol HTTP-GET. 
Jurnal Jaringan Telekomunikasi (Jurnal Jartel), E-ISSN: 2654-6531, P-ISSN: 2407-0807 Vol. 11, No. 1 (2021) 1-5

E. Perhitungan Besar Packet Data

TABEL V

BESAR PAKET DATA

\begin{tabular}{cc}
\hline Protocol & Besar Packet Data yang Dikirim \\
\hline HTTP-GET & 875 \\
MQTT & 129 \\
\hline Pengujian besar packet yang dikirim pada 2 protocol.
\end{tabular}

Pengujian besar packet yang dikirim pada 2 protocol. Hasil pembacaan data pada wireshark diketahui bahwa pada protocol MQTT besar packet data yang dikirim lebih kecil dari pada protocol HTTP-GET, ditunjukkan pada Tabel V.

\section{KESIMPULAN}

Aplikasi android digunakan untuk mengontrol pintu air yang akan dibuka dengan memeberi perintah berupa input jam berapa pintu akan dibuka. pintu air akan secara otomatis pula tertutup jika kelembabannya sudah mencapai batas yang ditentukan Pada pengujian didapatkan data yang terbaca dengan status relaynya sesuai dengan perencanaan, dan rata rata delay 0.799613 dan 0.1749775 . Sehingga dapat dikatakan system ini dapat berjalan cukup baik. Aplikasi android yang mendukung system relay sebegai pengontrol nyalanya pintu air berintegrasi dengan bagik dengan sensor Soil Moisture yang dirancang sebagai pembaca kelembaban dan pengatur status OFF relay saat digunakan dan dapat mengirimkan data yang diinginkan ke server dengan baik. Protocol MQTT yang dirancang untuk aplikasi otomatis buka pintu air ini bias berjalan dengan baik dan memiliki nilai QoS yang memiliki kualitas cukup baik dari segi delay yaitu 0.1749775 s, dan juga unggul dalam pengiriman besarnya packet data yang dikirim yaitu 129 bytes

\section{REFERENSI}

[1] A. Kadir, "Arduino", 2013, pp. 6-21

[2] P. Ilmiah, "Protoype Sistem Buka Tutup Pintu Air Otomatis," 2017.

[3] T. Beijing, "Engineering", 2006, vol. 40, no. 2, pp. 25652568. 